\title{
Archives of Gynecology and Obstetrics by the end of 2009
}

\author{
Hans Ludwig
}

Published online: 10 January 2010

(c) Springer-Verlag 2010

The reception and reviewing of manuscripts are done by the Editorial Manager System of Springer Publishers (http://www.editorialmanager.com/arch) since 2006 and "Archives" enjoys increasing attention which is shown in the rising numbers of manuscripts submitted in the last 4 years $(525 \rightarrow 1,375)$. However, the rejection rate is also higher than before $(36.2 \%$ in 2009 see Table 1$)$. The reviews received to any submission will be transmitted to the authors. Nearly all submissions have been at least once or even twice revised before being accepted; hence, the relatively small figure indicating definite rejection.

The journal has traditionally been devoted to the entire field of Gynecology and Obstetrics and as such compares itself with rather few journals of the same orientation in the world. Being formerly the scientific periodical for the German Gynecology and it, therefore, upholds the status being the "Organ of the German Society for Gynecology and Obstetrics", founded in 1885, until now. The origin of its authors spread far beyond the German-speaking countries and Europe. More frequently have been papers submitted from USA, United Kingdom, Japan, India, from Israel and Turkey. Most of them presenting research papers, besides short communications, letters and reviews out of their universities or associated clinics. The publisher prints twelve issues per year (150-200 pages each); the definitely revised paper in an issue is preceded by its online version appearing immediately after the positive conclusion of the editorial process.
Table 1 Manuscripts received and rejection rate

\begin{tabular}{lcc}
\hline Year & $\begin{array}{l}\text { Manuscripts } \\
\text { received }\end{array}$ & $\begin{array}{l}\text { Rejected after reviewing (average } \\
\text { 3 reviewers/submission) }(\%)\end{array}$ \\
\hline 2006 & 525 & $146(27.8)$ \\
2007 & 648 & $183(28.2)$ \\
2008 & 1,143 & $291(25.4)$ \\
2009 & 1,375 & $499(36.2)$ \\
$2006-2009$ & $3,696^{\text {a }}$ & $1,119(30.2)$
\end{tabular}

$\overline{{ }^{a} \text { Definite decisions made 3,552, pending assignments } 137 \text {, terminated } 7}$

To enable the reader, some further improvement of orientation, we did now introduce a system of classification within the distributed issues. The originals, reviews, and exceptional case reports will be listed according to their contents in:

\section{Materno-fetal Medicine \\ Gynecologic Oncology \\ General Gynecology \\ Reproductive Medicine}

We like to encourage our contributors and readers to continue to reflect on the subject matter and, if they so choose, write Short communications and Letters to the Editors which will be printed as soon as possible. Those letters might enhance in the scientific discussion.

31 December 2009 Hans Ludwig, Coordinating Editor

H. Ludwig $(\square)$

Wartenbergstrasse 9, 4052 Basel, Switzerland

e-mail: prof.ludwig@bluewin.ch 